the new development may help to broaden the pattern of grant-giving. The Ford Foundation's enterprise in bridging the usually sharp line between grant-giving and investment will be widely admired, but it will be interesting to see whether the US taxation authorities will allow private individuals to make loans to similar organizations and then to claim freedom or partial freedom from tax. In Britain, the new development will, first of all, be a problem for the Charity Commissioners, who have so far helped to create the view that investment and grant-giving should be kept apart.

\section{UNIVERSITY ENTRANCE}

\section{Scottish Requirements Standardized}

THe move by the eight Scottish universities in coming together in a new agreement on entrance policy should simplify the process of getting into university in Scotland. Last week the Scottish Inter-University Conference on the General Entrance Requirement announced that subject to Privy Council approval, the Scottish Universities Entrance Board which since 1919 has administered the entrance requirements of the four older universities-St Andrews, Glasgow, Aberdeen and Edinburgh-is to be dissolved. The certificate of Attestation of Academic Fitness (required for entry into these four universities) is also to be abolished.

In place of these will be the new Scottish Universities Council on Entrance, composed of three representatives from each of the eight universities-the original four plus Strathclyde, Heriot-Watt, Stirling and Dundee, which have all come into being since 1964 . The function of the council, which still needs approval from the general councils of the four older universities, will be to keep the universities informed on matters of entrance, and to cooperate with educational organizations outside the universities. The council will also administer the Scottish Universities Preliminary Examinations which, together with the newer Certificate of Scottish Education, is the academic hurdle immediately preceding application for university entrance in Scotland.

Instead of applying for a certificate of attestation, a candidate for admission to a Scottish university in October 1969 will immediately apply to the university of his choice, either directly or through the University Central Council on Admissions. $\mathrm{He}$ will be able to assess his eligibility to apply according to the statement of general entrance requirements which the eight universities have agreed upon. Later this statement is intended to include details of the specific subject requirements of the various faculties and courses of each Scottish university, which of course must still be satisfied before acceptance. The new council, unlike the board which it replaces, will not have the right to decide whether candidates comply with the general entrance requirements of the universities but will only be able to advise on the validity of academic qualifications for entrance.

As before, the general requirements for entrance are the equivalent of five passes in the Scottish Universities Preliminary Examinations of which three are at the higher grade, or four passes at the higher grade. There is a separate set of requirements for the University of Strathclyde and the Heriot-Watt University which do not insist on passes in such a wide range of subjects as the other six universities. Although the general require- ments as a whole will provide some increased latitude in choice of subjects, the traditional Scottish breadth of education will still be required. When specific faculty and course requirements are taken into account the situation for the applicant, in terms of the qualifications he must possess, will probably be little changed.

\section{MEDICAL ENGINEERING Towards Artificial Heart-Lungs}

from our Social Medicine Correspondent

A MIXED audience of medical workers, engineers and a sprinkling of officials from the Ministries of Health and Technology attended the conference "The Engineering Challenge of the Artificial Kidney and Lung Machine" held at the University of Leeds on October 3. Organized by the Yorkshire branch of the Institution of Chemical Engineers, the conference was held to mark the publication of the institution's fourth research report Chemical Engineering in Medicine, The Artificial Kidney and Lung Machines, by Dr J. R. Flower of the University of Leeds.

During the morning session, devoted to the artificial lung, Mr G. H. Wooler of Leeds Infirmary described various methods of assisting the circulation. He seemed satisfied with the machines available for perfusing adults, but emphasized the need for the development of smaller, equally safe machines for use with infants. This was followed by a descriptionfrom the engineer's point of view-of extracorporeal oxygenators by Dr Flower. With reference to the membrane oxygenators in which gas is separated from the blood by thin membranes of various permeable materials, he said that the chief problems to be overcome are the resistance which some membranes may offer to gas diffusion, possible blockage of the membrane by blood clots and the pressure drop across the membrane which may cause leakage either of gas or blood. Silicone rubber seems to be the most suitable material for the construction of membranes, and $\mathrm{Dr}$ Flower suggested that the principal challenge now is some means of packaging sufficient area of the membrane into a device which gives a thin uniform film of blood and which can pass about six litres of blood each minute.

Mr D. Longmore of the National Heart Hospital, London, talked about the future problems in heartlung machines from the surgeon's point of view. $\mathrm{He}$ believes that prolonged circulatory maintenance will become possible within the next year or two. For the time being, however, the main disadvantage of oxygenators is the damage they cause to erythrocytes. Mechanical injury causes most damage, but decreases in blood pressure caused by localized high velocities can lead to cavitation and evolution of gas, causing severe haemolysis.

After lunch, Dr R. Baillod of the Royal Free Hospital discussed the technical, medical and economic problems arising with artificial kidneys. Dr Flower then considered the designs of dialysers, pointing out where many of them fail. Among the more novel approaches is the "fibre kidney" developed by the Dow Corning Company in which the membrane consists of very small fibres of regenerated cellulose, a bundle of the fibres being held together by resin "tube-plates" cured in situ. Another advance is the successful develop- 
ment, by workers at the Massachusetts Institute of Technology, of a permeable, non-thrombogenic cellophane membrane. In the United Kingdom, the National Research Development Corporation is sponsoring the development of two new dialysers, one at the University of Strathclyde and the other at the University of Leeds.

In a deliberately provocative talk, Dr F. M. Parsons of the General Infirmary at Leeds declared that the capital cost of installing automatic kidney machines

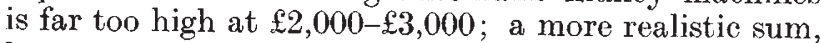
he suggested, would be about $£ 500-£ 1,000$. In view of the high demand for intermittent dialysis and the shortage of medical staff, he proposed that there should be continued expansion of home dialysis, and advocated the use of trained lay people to instruct patients on the use of home dialysers.

One of the chief points brought out during the lively discussions was the need for an interdisciplinary approach to the design of artificial lung and kidney devices. Engineers seem to feel that medical workers are not specific in their demands for devices, but another point of view is that it is still too early to standardize designs; for the time being at least, flexibility must be the keynote.

\section{CZECHOSLOVAK CONFERENCE \\ Biology of Bats}

THE following letter from the Czech organizers of the first International Bat Conference, held at Hluboká on September 6 to 9 , has been forwarded to Nature by Mr P. A. Racey of the Zoological Society of London, who managed to attend the meeting. Mr Racey says that, although only 12 of the 87 participants from 22 countries who had planned to attend found it possible to travel to Czechoslovakia, the original programme was followed as far as possible. The Czech scientists made it clear that they are anxious to maintain contact with their colleagues throughout the world no matter how difficult the political situation is, and the onus is now on the scientific communities of other countries to give as much practical support as possible to their Czech colleagues.

The statement, signed by Vladimír Hanák and Jiri Gaisler, says :

In spite of the present situation in Czechoslovakia, the Conference took place in the planned terms. The session was held on September 6, 1968, in the lecturing room of the Aleš Art Gallery at Hluboká. After the opening word by Dr W. Cerny, Chairman of the Czechoslovak Zoological Society, the following participants presented their papers: Mr Braaksma (Vreeswijk), Mr Daan (Amsterdam), Mr Dorgelo (Amsterdam), Dr Gaisler and Dr Hanák (Brno and Prague), Dr Neuweiler (Tübingen), Dr Novotný (Brno), Mr Racey (London) and Dr Roer (Bonn). An excursion through south Bohemia was made on September 7, 1968. A part of the participants then joined a trip to Moravia where they visited the caves in the Moravian Karst as well as south Moravia. In accordance with the original schedule, the Conference was closed at Lednice on September 9 .

The members of the Organizing Committee express their warm thanks to all who assisted them in their endeavours to organize this international meeting of scientists engaged in bat research. Our particular thanks are due to those colleagues from abroad who took part in the Conference in spite of the unfavourable conditions in Czechoslovakia. At the same time, we fully understand the reasons that prevented the remaining ones to participate. Due to the present circumstances, we intend to publish, above all, the papers read at the Conference. The originally announced papers that could not have been read will be published only in case that their authors have no other possibility of publishing them. Their manuscripts in a limited extent should be sent to Dr V. Hanák, Institute of Systematic Zoology, Charles University, Viniené 7, Praha, Czechoslovakia, before November 30, 1968.

The participants of the Conference have approved that an endeavour should be made to organize the Second International Bat Research Conference in some of the western countries (e.g., the Netherlands), in future years.

\section{FISHERIES}

\section{Saving the Spurdog}

Fisf and chip shops in the south of England could be the principal losers if measures to conserve the spurdog are not taken by the fishing authorities. The spurdog, Squalus acanthias, is an elasmobranch fish commonly known to Londoners as "rock salmon". There are several stocks of spurdog in the north-east Atlantic, but one stock is particularly at risk-the ScottishNorwegian stock inhabiting the sea area from the Norwegian coast to west of the Shetland, Orkney and Hebridean Islands. This stock has been heavily fished by the English, Scots and Norwegians since 1952.

Mr M. J. Holden of the Fisheries Laboratory at Lowestoft now argues that unless there is a severe restriction of fishing, there will be a "drastic and continuing decline in the stock". In a recent report (Fishery Invest. (ser. 11), 25 (8); 1968. HMSO, 11s.6d.) Mr Holden suggested ways of stopping the decline. Estimates were made of the fishing and natural mortal. ity coefficients for the stock and the present rate of decrease of the stock was then calculated. To stop the decline, recruitment to the stock will have to be maintained, but while it is obviously necessary to protect the female fish to ensure replication, it is also necessary to take the male fish into account. This is where complications arise.

The male fish reach a smaller maximum length than the females, and therefore protection of the stock by the imposition of a minimum size limit, irrespective of sex but sufficient to protect the female fish, could result in the under-exploitation of the males. To stabilize the stock and to give a maximum yield at the present level of fishing, Mr Holden has therefore calculated separate size limits for each sex; one of 56 $\mathrm{cm}$ for the males and one of $80 \mathrm{~cm}$ for the females. Even though the sexes are easily distinguishable, it would in practice be difficult to enforce two size limits. $\mathrm{Mr}$ Holden has therefore calculated one size limit which would allow both the exploitation of the stock and the maintenance of recruitment. The best compromise minimum size limit would be $78 \mathrm{~cm}$, but to maintain recruitment the numbers of females kept by fishermen would have to be reduced. This may be asking a lot of human nature. 